\title{
Analisis Pengaruh Proses Sintering Terhadap Struktur Bijih Mangan Yang Berasal Dari Nagari Aie Ramo, Kecamatan Kamang Baru, Kabupaten Sijunjung
}

\author{
Mustofa $^{1, *}$, Dwi Puryanti', Arif Budiman ${ }^{2}$ \\ ${ }^{1}$ Laboratorium Fisika Material, Jurusan Fisika \\ ${ }^{2}$ Laboratorium Fisika Bumi, Jurusan Fisika \\ Fakultas Matematika dan Ilmu Pengetahuan Alam Universitas Andalas \\ Kampus Unand Limau Manis, Padang, 25163, Indonesia \\ *tofamustofal@gmail.com
}

\begin{abstract}
ABSTRAK
Penelitian ini untuk menganalisis pengaruh proses sintering terhadap struktur bijih mangan dari Nagari Aie Ramo, Kecamatan Kamang Baru, Kabupaten Sijunjung. Sampel yang digunakan berupa serbuk bijih mangan hasil ayakan 250 mesh. Penelitian ini menggunakan peralatan XRF dan XRD untuk karakterisasi. Hasil XRF menunjukkan bahwa kadar mangan totalnya bernilai ekonomis yaitu sebesar 79,70\%. Kadar mangan total mengalami peningkatan dengan meningkatkannya suhu sintering. Mineral bijih mangan tanpa sintering berupa pirolusit, coesit, psilomelan, dan braunit. Kemudian akibat sintering $600^{\circ} \mathrm{C}$ terbentuk rodonit, bixbit dan braunit. Rodonit terbentuk karena mineral pirolusit berikatan dengan coesit. Mineral bixbit muncul karena pirolusit dipanaskan diatas $400^{\circ} \mathrm{C}$. Mineral braunit semakin jelas orientasinya dalam difraktogram. Pada sintering $800^{\circ} \mathrm{C}$, terdapat hausmanit, bixbit, rodonit, dan braunit. Pada suhu $1.000^{\circ} \mathrm{C}$, ditemukan dua mineral yaitu hausmanit dan braunit. Sintering menyebabkan terjadinya proses oksidasi terhadap mineral mangan. Sehingga terjadi perubahan struktur kristalnya.

Kata kunci : bijih mangan sijunjung, sintering, struktur kristal mangan
\end{abstract}

\section{ABSTRACT}

This research has conducted to analyze the effect of sintering process to manganese ore structure from Nagari Aie Ramo, Kecamatan Kamang Baru, Sijunjung. Samples form is manganese ore powder of 250 mesh sieve. This study methods used XRF and XRD equipment for characterization. XRF results show that total manganese content is economical value that is equal to $79.70 \%$. Total manganese content increases with increasing sintering temperature. Manganese ore minerals without sintering in the form of pyrolysite, coesite, psilomelan, and braunit. Then due to sintering at $600^{\circ} \mathrm{C}$ forms rodonite, bixbit and braunit. Rodonite is formed when the pyrolysite mineral binds to coesite. Bixbit mineral arises when the pyrolysite is heated above $400^{\circ} \mathrm{C}$. The braunite mineral has clear appearance in the difractogram results. At sintering $800^{\circ} \mathrm{C}$, there is hausmanite, bixbit, rodonite, and braunite. At least, when the temperature of sintering at $1.000^{\circ} \mathrm{C}$, it has found two minerals : hausmanite and braunit. Sintering causes oxidation reactions to manganese minerals and there is change on crystal sctructure.

Keywords: manganese sijunjung ore, sintering, manganese crystal structure

\section{PENDAHULUAN}

Mangan merupakan salah satu unsur yang penting dalam kehidupan manusia. Mangan dimanfaatkan secara luas dalam bidang industri. Hampir $85 \%$ hasil produksi mangan digunakan dalam industri produksi baja (Fitri, 2016). Manfaat mangan sangat banyak, diantaranya sebagai bahan antikarat dan baterai alkali (Rochani, 2012), perangkat elektronik (Sam dan Nesaraj, 2011), produksi superkapasitor (Menaka, 2011), bahan baku industri baja (Keenan, 1992), depolarizer sel kering baterai, reagent laboratorium, pencelupan tekstil, menghilangkan warna hijau pada gelas akibat pengotor besi (Hawley, 2001), dan mangan sangat penting dalam penggunaan Vitamin $\mathrm{B}_{1}$ karena $\mathrm{Mn}, \mathrm{Ca}$, dan $\mathrm{P}$ bersama-sama membentuk sistem tulang (Panjaitan, 2011).

Mangan ditemukan dalam bentuk bijih mangan yang berwujud batuan. Bijih mangan terbentuk dalam tiga tipe yaitu hidrotermal, sedimenter, dan residu. Secara umum bijih mangan diklasifikasikan menjadi tiga golongan yaitu mangan oksida, mangan silikat, dan mangan karbonat. Mangan oksida yaitu bijih mangan dengan kompoisi oksida dan paling banyak ditemukan contohnya, pirolusit, psilomelan, dan bixbit. Mangan silikat adalah bijih mangan yang mengandung silikat contohnya, braunit dan rodonit. Mangan karbonat adalah mangan yang mengandung karbonat contohnya adalah rodokrosit. Menurut Panjaitan (2011) terdapat 
empat jenis bijih mangan yang bernilai ekonomis yaitu pirolusit, psilomelan, rodokrosit, dan rodonit.

Berdasarkan data Kementerian Energi dan Sumber Daya Mineral (ESDM) tahun 2015, potensi bijih mangan di Indonesia mencapai 15.557.048 ton. Bijih mangan tersebut tersebar di banyak daerah diantaranya Nusa Tenggara Timur, Yogyakarta, dan Sumatera Barat. Sumatera Barat salah satu daerah dengan potensi bijih mangan mencapai 5.417,65 ton (BPS, 2016). Potensi ini tersebar di beberapa daerah seperti Pasaman Barat (Gunung Tuleh), Dharmasraya (Timpeh), dan Sijunjung (Tanjung Gadang dan Kamang Baru). Menurut data Badan Pusat Statistik (2016), luas daerah potensi bijih mangan di Kabupaten Sijunjung mencapai 175 Ha. Bijih mangan ini dikelola melalui tambang rakyat sehingga eksploitasinya masih bersifat raw material yang berdampak pada nilai jualnya masih rendah.

Penelitian terkait bijih mangan di Sumatera Barat pernah dilakukan oleh Putri, dkk (2015). Sampelnya adalah bijih mangan dari Kecamatan Gunung Tuleh (Pasaman Barat). Penelitian ini untuk menganalisis struktur bijih mangan hasil proses sintering dengan variasi suhu yaitu $600^{\circ} \mathrm{C}, 700^{\circ} \mathrm{C}, 800^{\circ} \mathrm{C}, 900^{\circ} \mathrm{C}$, dan $1.000^{\circ} \mathrm{C}$. Hasilnya diperoleh bahwa kadar mangan sebesar $42,20 \%$. Mineral bijih mangan sebelum disinter berupa pirolusit dan coesit. Sintering $600^{\circ} \mathrm{C}$ diperoleh mineral braunit, bixibit, dan rodonit. Sintering $700^{\circ} \mathrm{C}$ dan $800^{\circ} \mathrm{C}$ menghasilkan mineral yang sama yaitu braunit, bixbit, rodonit, dan hausmanit. Sintering $900^{\circ} \mathrm{C}$ diperoleh mineral braunit, bixbit dan hausmanit. Sintering $1.000^{\circ} \mathrm{C}$ diperoleh mineral braunit dan hausmanit.

Berdasarkan uraian di atas maka perlu dilakukan penelitian dengan sampel bijih mangan dari Nagari Aie Ramo, Kecamatan Kamang Baru, Kabupaten Sijunjung. Penelitian ini untuk mengetahui komposisi bijih mangan dan pengaruh proses sintering terhadap perubahan struktur bijih mangan dengan variasi suhu. Kadar mangan dan perubahan akibat sintering inilah yang diharapkan bermanfaat dalam bidang industri. Sebab proses sintering dapat menyebabkan atom-atomnya berdifusi (Ramlan, 2001). Selain itu, sintering juga dapat memperkecil atau menghilangkan pori (Ramlan dan Akhmad, 2011).

\section{METODE}

Bijih mangan yang digunakan berasal dari Nagari Aie Ramo, Kecamatan Kamang Baru, Kabupaten Sijunjung. Bijih mangan ini diperoleh dari pengepul hasil tambang. Bijih mangan ini kemudian dicuci dengan air bersih. Bijih mangan kemudian dijemur hingga kering, kemudian digerus menggunakan mesin gerinding. Hal ini bertujuan agar diperoleh sampel berupa serbuk. Sampel serbuk kemudian diayak dengan ayakan 250 mesh agar diperoleh ukuran butir yang homogen. Hasil ayakan ini kemudian dicuci dengan aquades untuk menghilangkan pengotor selama penggerusan. Setelah kering, sampel serbuk kemudian disintering dengan variasi suhu $600^{\circ} \mathrm{C}, 800^{\circ} \mathrm{C}$, dan $1.000^{\circ} \mathrm{C}$ dengan waktu tunggu $1,5 \mathrm{jam}$. Kemudian sampel ini diberi label, yaitu A(tanpa sintering), B $\left(\mathrm{T}=600^{\circ} \mathrm{C}\right), \mathrm{C}\left(\mathrm{T}=800^{\circ} \mathrm{C}\right)$, dan $\mathrm{D}\left(\mathrm{T}=1.000^{\circ} \mathrm{C}\right)$. Sampel ini masingmasing dikarakterisasi menggunakan XRF dan XRD. XRF untuk mengetahui komposisi bijih mangan. XRD untuk mengetahui struktur kristal bijih mangan. Proses analisis hasil XRD menggunakan program High Score Plus.

\section{HASIL DAN DISKUSI}

\subsection{Hasil Pengukuran X-Ray Fluoresence (XRF) Terhadap Bijih Mangan}

Hasil pengukuran menggunakan XRF menunjukkan bijih mangan mengandung mangan $(\mathrm{Mn})$, besi $(\mathrm{Fe})$, aluminium $(\mathrm{Al})$, silikat $(\mathrm{Si})$, kalium $(\mathrm{K})$, barium $(\mathrm{Ba})$, Fosfor $(\mathrm{P})$, magnesium $(\mathrm{Mg})$, kalsium $(\mathrm{Ca})$, dan titanium $(\mathrm{Ti})$ dengan kadar seperti dalam Tabel 1. Kadar mangan yang diperoleh termasuk cukup tinggi. Kadar mangan total tanpa sintering mencapai 79,70\%. Hasil ini lebih baik bila dibandingan dengan kadar mangan dibeberapa daerah lainnya, seperti Bleber (74,19\%) (Ansori, 2010), Pasaman Barat (42,20\%) (Putri, dkk., 2015), dan Timpeh (60,42\%) (Kisman, 2016). Kadar mangan dari Nagari Aie Ramo sangat potensial dikembangkan menjadi usaha tambang. Sebab kadar mangannya bernilai ekonomis yaitu $\geq 45 \%$ (Arief, dkk., 2011). Kadar mangan mengalami peningkatan setelah dilakukan sintering. Kadar mangan tanpa sintering sebesar $79,70 \%$. Pada suhu $600^{\circ} \mathrm{C}$ terjadi peningkatan kadar mangan menjadi $80,30 \%$. 
Pada suhu $800^{\circ} \mathrm{C}$ diperoleh kadar mangan sebesar $81,10 \%$. Pada suhu $1.000^{\circ} \mathrm{C}$ diperoleh kadar mangan sebesar $82,40 \%$. Hal ini dipengaruhi oleh penurunan persentase dari unsur penyusun bijih mangan, seperti Fe, Al, Si, K, B, dan Mg.

Tabel 1 Hasil XRF Terhadap Bijih Mangan

\begin{tabular}{cccccc}
\hline & & \multicolumn{4}{c}{ Kadar Bijih Mangan $(\%)$} \\
\cline { 3 - 6 } No & Unsur & Tanpa Sintering & $600^{\circ} \mathrm{C}$ & $800^{\circ} \mathrm{C}$ & $1.000^{\circ} \mathrm{C}$ \\
\hline 1. & $\mathrm{Mn}$ & 79,70 & 80,30 & 81,10 & 82,40 \\
2. & $\mathrm{Fe}$ & 13,50 & 12,50 & 12,00 & 11,20 \\
3. & $\mathrm{Al}$ & 2,62 & 2,82 & 2,64 & 2,37 \\
4. & $\mathrm{Si}$ & 2,21 & 2,24 & 2,07 & 1,60 \\
5. & $\mathrm{~K}$ & 1,30 & 1,31 & 1,54 & 1,50 \\
6. & $\mathrm{Ba}$ & 0,36 & 0,35 & 0,34 & 0,42 \\
7. & $\mathrm{P}$ & 0,15 & 0,16 & 0,16 & 0,29 \\
8. & $\mathrm{Mg}$ & 0,10 & 0,11 & 0,11 & 0,10 \\
9. & $\mathrm{Ca}$ & 0,08 & 0,10 & 0,05 & 0,08 \\
10. & $\mathrm{Ti}$ & 0,02 & 0,02 & 0,02 & 0,02 \\
\hline
\end{tabular}

\subsection{Hasil Pengukuran XRD Terhadap Bijih Mangan}

Pada pengukuran ini diperoleh nilai a, $\mathrm{b}, \mathrm{c}, \alpha, \beta, \gamma$, komposisi mineral dan sistem kristalnya. Hasil pengukuran bijih mangan menggunakan XRD dapat dilihat dalam Tabel 2.

Tabel 2 Hasil Pengukuran XRD terhadap Bijih Mangan

\begin{tabular}{|c|c|c|c|c|c|c|c|c|}
\hline \multirow[t]{2}{*}{ Suhu } & \multirow{2}{*}{$\begin{array}{c}\text { Komposisi } \\
\text { Mineral }\end{array}$} & \multicolumn{6}{|c|}{ Struktur } & \multirow{2}{*}{$\begin{array}{l}\text { Sistem } \\
\text { Kristal }\end{array}$} \\
\hline & & $a(\AA)$ & $b(\AA)$ & $c(\AA)$ & $\alpha\left(^{\circ}\right)$ & $\beta\left(^{\circ}\right)$ & $\gamma\left({ }^{\circ}\right)$ & \\
\hline Tanpa & Pirolusit & 4,380 & 4,380 & 2,850 & 90,00 & 90,00 & 90,00 & Tetragonal \\
\hline \multirow[t]{3}{*}{ Sintering } & Psilomelan & 9,560 & 2,880 & 13,850 & 90,00 & 92,50 & 90,00 & Monoklinik \\
\hline & Coesit & 7,173 & 12,328 & 7,175 & 90,00 & 120,00 & 90,00 & Monoklinik \\
\hline & Braunit & 9,420 & 9,420 & 18,670 & 90,00 & 90,00 & 90,00 & Tetragonal \\
\hline \multirow[t]{3}{*}{$600^{\circ} \mathrm{C}$} & Rodonit & 7,699 & 12,220 & 6,702 & 93,97 & 93,07 & 68,20 & Triklinik \\
\hline & Bixbit & 9,416 & 9,423 & 9,405 & 90,00 & 90,00 & 90,00 & Ortorhombik \\
\hline & Braunit & 9,420 & 9,420 & 18,670 & 90,00 & 90,00 & 90,00 & Tetragonal \\
\hline \multirow[t]{4}{*}{$800^{\circ} \mathrm{C}$} & Hausmanit & 5,750 & 5,750 & 9,420 & 90,00 & 90,00 & 90,00 & Tetragonal \\
\hline & Rodonit & 9,758 & 10,499 & 12,205 & 108,58 & 102,92 & 82,52 & Triklinik \\
\hline & Bixbit & 9,411 & 9,411 & 9,411 & 90,00 & 90,00 & 90,00 & Kubik \\
\hline & Braunit & 9,420 & 9,420 & 18,670 & 90,00 & 90,00 & 90,00 & Tetragonal \\
\hline \multirow[t]{2}{*}{$1.000^{\circ} \mathrm{C}$} & Hausmanit & 5,762 & 5,762 & 9,470 & 90,00 & 90,00 & 90,00 & Tetragonal \\
\hline & Braunit & 9,420 & 9,420 & 18,670 & 90,00 & 90,00 & 90,00 & Tetragonal \\
\hline
\end{tabular}

\subsubsection{Tanpa Sintering}

Sampel bijih mangan tanpa sintering diperoleh mineral yaitu pirolusit $\left(\mathrm{MnO}_{2}\right)$, psilomelan $\left(\mathrm{Ba}_{\mathrm{x}} \mathrm{Mn}_{2} \mathrm{O}_{10} .2 \mathrm{H}_{2} \mathrm{O}\right)$, coesit $\left(\mathrm{SiO}_{2}\right)$, dan braunit $\left(\left(\mathrm{Mn}_{2} \mathrm{O}_{3}\right)_{3} \mathrm{MnSiO}_{3}\right)$. Berdasarkan hasil XRD diperoleh puncak tertinggi difraksi pada sudut $2 \theta$ yaitu $37,4364^{\circ}$. Hasil XRD sampel bijih mangan tanpa sintering dapat dilihat dalam Gambar 1. Hasil XRD menampilkan bahwa mineral braunit selalu ada pada semua puncak difraktogram. Hal ini menunjukkan bahwa sampel bijih mangan didominasi mineral braunit. Mineral braunit memiliki sistem kristal tetragonal. Sistem kristal tetragonal berarti $a=b \neq c$. Kemudian nilai sudut $\alpha, \beta$, dan $\gamma$ adalah sama $\left(90^{\circ}\right)$. 


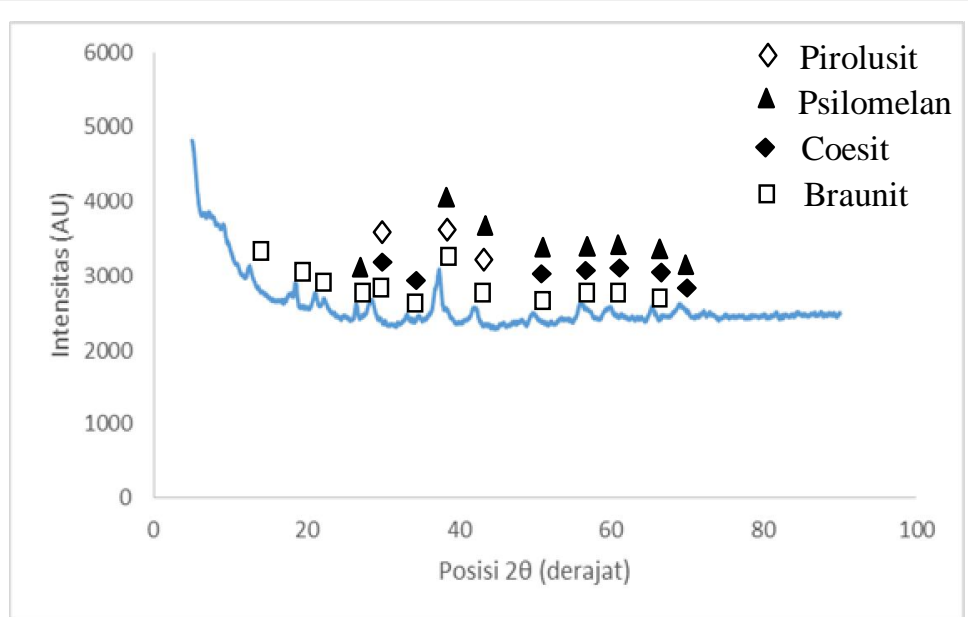

Gambar 1 Hasil XRD tanpa sintering

Mineral pirolusit memiliki sistem kristal tetragonal. Mineral ini memiliki panjang $\mathrm{a}=\mathrm{b}$

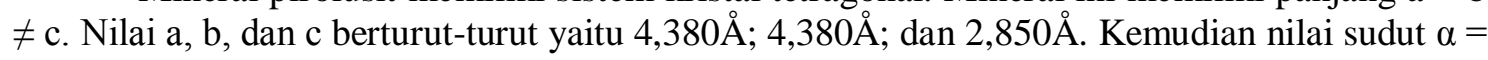
$\beta=\gamma=90^{\circ}$. Mineral psilomelan memiliki sistem kristal monoklinik. Sistem kristal ini memiliki nilai $\mathrm{a} \neq \mathrm{b} \neq \mathrm{c}$. Nilai $\mathrm{a}, \mathrm{b}$, dan c berturut-turut yaitu $9,560 \AA$; $2,880 \AA$; dan $13,850 \AA$. Sistem kristal monoklinik memiliki nilai $\alpha=\gamma \neq \beta$. Masing-masing nilai $\alpha, \beta$, dan $\gamma$ adalah $90^{\circ}, 92,50^{\circ}$, dan $90^{\circ}$. Mineral coesit memiliki sistem kristal monoklinik dengan panjang nilai $\mathrm{a} \neq \mathrm{b} \neq \mathrm{c}$. Nilai

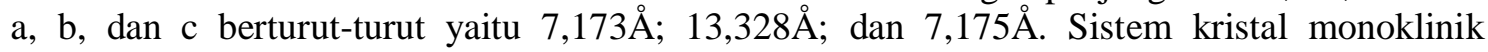
memiliki nilai $\alpha=\gamma \neq \beta$. Masing-masing nilai $\alpha, \beta$, dan $\gamma$ adalah $90^{\circ}, 120^{\circ}$, dan $90^{\circ}$. Nilai a, b, c, $\alpha, \beta$, dan $\gamma$ dapat dilihat dalam Tabel 2 .

\subsubsection{Sintering $600^{\circ} \mathrm{C}$}

Hasil XRD pada sintering $600^{\circ} \mathrm{C}$ diperoleh mineral yaitu rodonit $(\mathrm{MnSiO} 3)$, bixbit (Mn2O3), dan braunit ((Mn2O3)3MnSiO3). Puncak tertinggi difraksi diperoleh pada sudut $2 \theta$ yaitu $32,8917^{\circ}$. Pada puncak ini ukuran kristal semakin besar dengan satu orientasi karena puncak difraksi yang mendekati garis vertikal (Abdullah, 2009). Hasil XRD sampel ini dapat dilihat dalam Gambar 2. Mineral rodonit (MnSiO3) berstruktur triklinik terbentuk akibat difusi mineral pirolusit dengan coesit (Putri, dkk., 2015). Difusi atom-atom ini akibat proses sintering (Ramlan, 2001). Sistem kristal triklinik memiliki panjang $\mathrm{a} \neq \mathrm{b} \neq \mathrm{c}$ dan $\alpha \neq \beta \neq \gamma$.

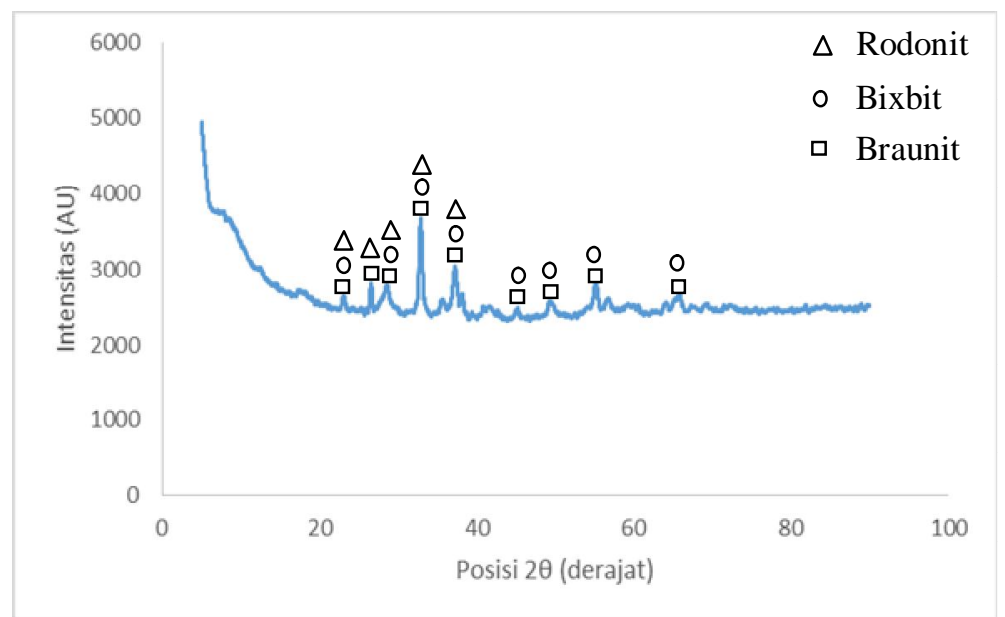

Gambar 2 Hasil XRD sintering $600^{\circ} \mathrm{C}$

Sintering di atas $400^{\circ} \mathrm{C}$ akan mengubah pirolusit menjadi bixbit (Wahyudi, 2008). Sintering menyebabkan terjadinya reaksi oksidasi. Akibatnya ion-ion Mn mengalami peningkatan. Pirolusit dibangun oleh $\mathrm{Mn}+2$ meningkat menjadi $\mathrm{Mn}+3$ (bixbit). Proses sintering juga mengakibatkan perubahan koordinasi atom-atom dalam unit selnya (Putri, dkk., 2015). 
Pirolusit berstruktur tetragonal berubah menjadi bixbit berstruktur ortohombik $(\mathrm{a} \neq \mathrm{b} \neq \mathrm{c}$ dan $\alpha$ $=\beta=\gamma=90^{\circ}$ ). Perubahan struktur ini diakibatkan oleh pemberian panas yang menyebabkan pembubaran atau disolusi atom pada area oksidasi atau pertukaran ion (Grimsley, dkk., 1977). Mineral braunit memiliki struktur tetragonal. Kristal ini memiliki nilai $\mathrm{a}=\mathrm{b} \neq \mathrm{c}$ dan $\alpha=\beta=\gamma=$ $90^{\circ}$. Nilai a, b, c, $\alpha, \beta$, dan $\gamma$ dapat dilihat dalam Tabel 2 .

\subsubsection{Sintering $800^{\circ} \mathrm{C}$}

Hasil XRD pada sampel sintering $800^{\circ} \mathrm{C}$ diperoleh mineral yaitu hausmanit (Mn3O4), rodonit (MnSiO3), bixbit (Mn2O3), dan braunit ((Mn2O3)3MnSiO3). Berdasarkan hasil XRD diperoleh puncak tertinggi difraksi pada sudut $2 \theta$ pada $33,0717^{\circ}$. Hasil XRD sampel ini dapat dilihat dalam Gambar 3. Hasil difraktogram menunjukkan ukuran kristal semakin besar dengan satu orientasi karena puncak difraksi yang mendekati garis vertikal (Abdullah, 2009).

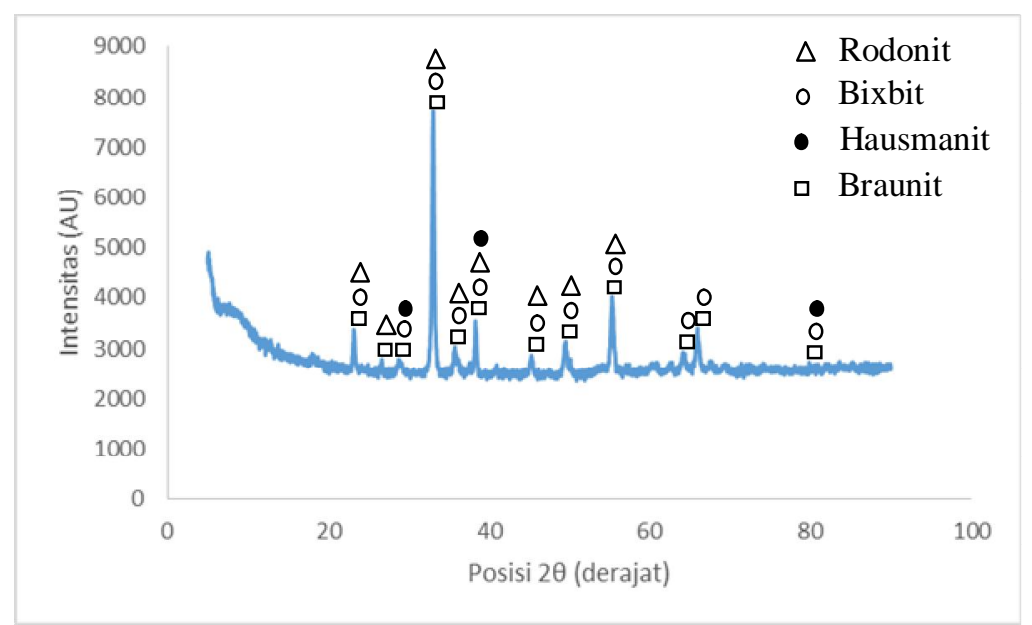

Gambar 3 Hasil XRD sintering $800^{\circ} \mathrm{C}$

Sintering $400^{\circ} \mathrm{C}$ akan mengubah bixbit menjadi hausmanit (Wahyudi, 2008). Proses sintering menyebabkan terjadinya reaksi oksidasi pada pembentukan hausmanit. Hal ini menyebabkan ion-ion Mn meningkat. Bixbit yang memiliki ion $\mathrm{Mn}+3$ meningkat menjadi Mn+4 membentuk hausmanit (Putri, dkk., 2015). Mineral hausmanit memiliki sistem kristal tetragonal $\left(\mathrm{a}=\mathrm{b} \neq \mathrm{c}\right.$ dan $\left.\alpha=\beta=\gamma=90^{\circ}\right)$.

Sintering diatas $400^{\circ} \mathrm{C}$ akan mengubah pirolusit menjadi bixbit (Wahyudi, 2008). Pirolusit dibangun oleh ion $\mathrm{Mn}+2$ dan Bixbit dibangun ion $\mathrm{Mn}+3$. Terbentuknya mineral bixbit akibat atom-atom pirolusit bergetar akibat pemanasan. Hal ini menyebabkan ion-ion $\mathrm{Mn}$ mengalami peningkatan. Pirolusit Mn+2 meningkat menjadi bixbit Mn+3 (Putri, dkk. 2015). Perubahan struktur pirolusit (tetragonal) berubah menjadi bixbit (kubik) akibat proses oksidasireduksi selama pemanasan (Putri, dkk., 2015). Bixbit berstruktur kubik memiliki nilai $\mathrm{a}=\mathrm{b}=\mathrm{c}$ $=9,411 \AA$. Nilai sudut-sudutnya juga sama, yaitu $\alpha=\beta=\gamma=90^{\circ}$. Mineral rodonit $(\mathrm{MnSiO} 3)$ dengan struktur kristal triklinik muncul akibat difusi mineral pirolusit (tetragonal) dengan coesit (monoklinik). Rodonit termasuk dalam golongan mangan silikat yang berstruktur kristal triklinik (anorthite). Mineral rodonit memiliki nilai $\mathrm{a} \neq \mathrm{b} \neq \mathrm{c}$ dan $\alpha \neq \beta \neq \gamma$. Nilai $\mathrm{a}, \mathrm{b}, \mathrm{c}, \alpha, \beta$, dan $\gamma$ dapat dilihat dalam Tabel 2.

\subsubsection{Sintering $1.000^{\circ} \mathrm{C}$}

Pada sintering $1.000^{\circ} \mathrm{C}$ diperoleh hasil XRD berupa mineral hausmanit (Mn3O4) dan braunit ((Mn2O3)3MnSiO3). Berdasarkan hasil XRD diperoleh puncak tertinggi difraksi pada sudut $2 \theta$ yaitu $32,9366^{\circ}$. Pada puncak tertinggi hanya ditemukan mineral braunit. Hasil XRDnya dapat dilihat dalam Gambar 4. Hasil difraktogram menunjukkan ukuran kristal braunit semakin besar dengan satu orientasi karena puncak difraksi yang mendekati garis vertikal (Abdullah, 2009). 


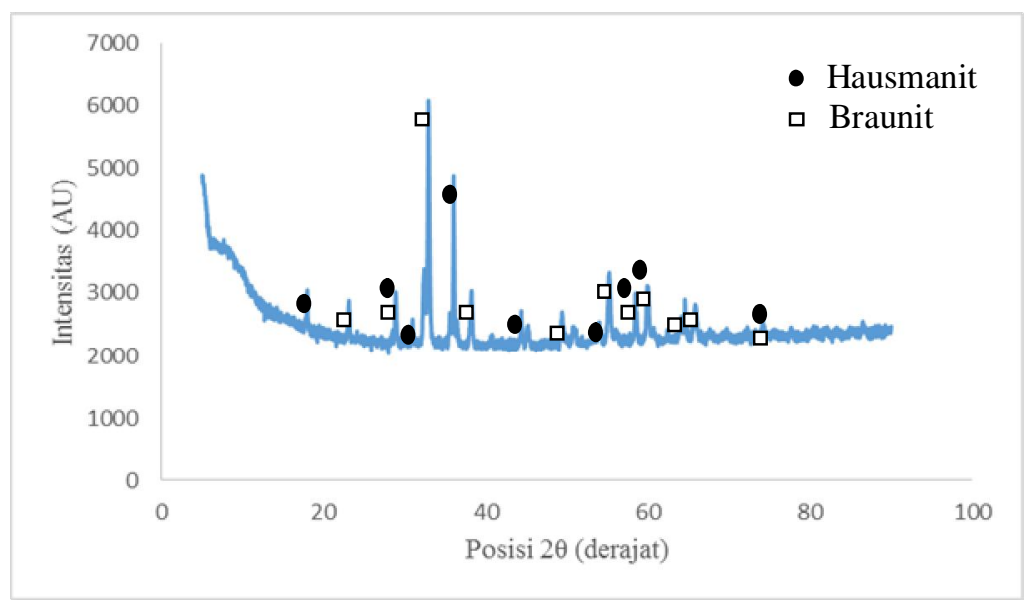

Gambar 4 Hasil XRD sintering $1000^{\circ}$

Mineral braunit pada sintering $1.000^{\circ} \mathrm{C}$ terbentuk dengan dua cara. Pertama, mineral bixbit berdifusi dengan mineral rodonit (Wahyudi, dkk., 2013). Kedua, mineral hausmanit berikatan dengan rodonit (Putri, dkk., 2015). Penggabungan mineral ini akibat pemanasan dengan suhu tinggi, yaitu $1.000^{\circ} \mathrm{C}$. Mineral braunit yang terbentuk berstruktur tetragonal. Sistem kristal ini memiliki nilai $\mathrm{a}=\mathrm{b} \neq \mathrm{c}$. Selanjutnya nilai-nilai sudutnya adalah sama $(\alpha=\beta=$ $\gamma=90^{\circ}$ ). Mineral hausmanit terbentuk karena mineral bixbit berstruktur kubik bertransformasi menjadi hausmanit. Transformasi mineral ini akibat sintering. Panas yang diterima digunakan untuk melakukan reaksi oksidasi. Nilai a, b, c, $\alpha, \beta$, dan $\gamma$ dapat dilihat dalam Tabel 2.

\section{KESIMPULAN}

Berdasarkan penelitian ini dapat disimpulkan bahwa kadar mangan dalam bijih mangan hasil tambang yang diperoleh dari pengepul di Nagari Aie Ramo, Kecamatan Kamang Baru, Kabupaten Sijunjung sebesar 79,70\%. Meningkatnya suhu sintering menyebabkan kadar mangan meningkat. Hal ini dipengaruhi oleh menurunnya persentase unsur-unsur penyusun bijih mangan, seperti $\mathrm{Fe}, \mathrm{Si}, \mathrm{Al}, \mathrm{Ba}, \mathrm{Mg}, \mathrm{K}$, dan $\mathrm{Mg}$. Meningkatnya suhu sintering akan mempengaruhi perubahan struktur mineral bijih mangan. Jenis bijih mangan tanpa sintering yaitu pirolusit (tetragonal), psilomelan (monoklinik), coesit (monoklinik), dan braunit (tetragonal). Pada sintering $600^{\circ} \mathrm{C}$ terbentuk mineral mangan baru yaitu rodonit (triklinik), bixbit (ortorombik), dan braunit (tetragonal). Pada sintering $800^{\circ} \mathrm{C}$ diperoleh mineral hausmanit (tetragonal), rodonit (triklinik), bixbit (kubik), dan braunit (tetragonal). Pada sintering $1.000^{\circ} \mathrm{C}$ diperoleh dua mineral mangan yaitu hausmanit (tetragonal) dan braunit (tetragonal).

\section{DAFTAR PUSTAKA}

Abdullah, M., 2009, Pengantar Nanosains, Bandung : ITB

Ansori, C, 2010, Potensi Geneasis Mangan di Kawasan Kars Gombong Selatan Berdasarkan Penelitin Geologi Lapangan Analisis Data Induksi Polarisasi dan Kimia Mineral, Buletin Sumber Daya Geologi Vol : 5, No.2.

Arief, R., Suhandi, Candra, P., 2011, Penelitian Bahan Galian Lain Dan Mineral Ikutan Pada Wilayah Pertambangan Di Kabupaten Minahasa Utara, Sulawesi Utata, Jurnal Kelompok Penyelidikan Konservasi dan Unsur Tanah Jarang, Pusat Sumber Daya Geologi.

Badan Pusat Statistik, 2016,Provinsi Sumatera Barat Dalam Angka, hal 546.

Fitri, I, 2016, Analisis Kandungan Mineral Logam Singkapan Bauan di Kawasan Pertambangan Mangan Desa Kumbewaha Kecamatan Siotapina Kabupaten Buton Dengan Menggunakan XRF. Skripsi, Universitas Haluleo : Kendari.

Grimsley, W.D., J. B. See, dan R. P. King, 1977, The Mechanism and Rate ofreduction of mamatwan manganese ore fines by carbon, Journal Of The South African Institute of mining And Metallurgy

Hawleys, 2001, Condensed Chemical Dictionary, Fourteenth edition. John Willey, Canada, 
Keenan, C. W., Kleinfelter D. C., Wood J., 2005, Ilmu Kimia Untuk Universitas, Jilid 2,

Edisi Keenam, Alih Bahasa oleh Aloysius Hadyana Pudjaatmaka, Jakarta : Erlangga Kementrian ESDM. 2015. Indonesia Mineral and Coal Information 2015, Departemen Jenderal Mineral dan Batubara, Hal: 5.

Kisman, Bambang P., dan Edya P., 2016, Prospeksi Mangan Di Kecamatan Timpeh, Kabupaten Dharmasraya, Provinsi Sumatera Barat. Jurnal Kelompok Penyelidikan Mineral, Pusat Sumber Daya Geologi

Menaka, S. L. Samal, K. V Ramanujachary, S. E. Lofland, Govind, dan A. K Ganguli, 2011, Stabilization of Mn (IV) in Nanostructured Zinc Manganesse oxide and Their Facile Transformation from Nanosphere to Nanorods, Journal of Materials Chemistry. Vol : 21, Page 8566-8573, Departement of Chemistry, Indian Institute of Technology : New Delhi.

Panjaitan, R. R., 2011. Kajian Pemanfaatan Batu Mangan (Senyawa Mangan Dalam Industri). Vol : 11 No.2. Litbang Industri. Baristand Industri Surabaya

Putri, P. J., Ratnawulan, dan Gusnedi, 2015 Analisis truktur Bijih Mangan Hasil Proses Sinter Yang terdapat di Nagari Kiawai Kecamatan Gunung Tuleh Kabupaten Pasaman Barat. Pilar of Physiscs, Vol: 5, hal : 105-112.

Rochani, S., 2015. Potensi Pengemabangan Pengolahan dan Pemurnian Bijih Mangan di Indonesia. Vol : 13, No. 3.

Ramlan, 2001, Pengaruh $\mathrm{MgO}$ dan suhu sinterng terhadap Mikrostruktur dan sifat fisik keramik Beta Alumna ( $\beta$-Alumina), Tesis Magiser Ilmu Material, Universitas Indonesia

Ramlan, dan Akhmad A.B., 2011, Pengaruh suhu dan waktu sintering terhadap sifat bahan porselen untuk bahan elektrolit padat (Komponen Elketronik), Jurnal Fisika FMIPA UNSRI, Vol: 14 No. 3B 14305, Palembang : FMIPA UNSRI

Sam, S., Nesaraj, S. A., Preparation of $\mathrm{Mn}_{2} \mathrm{FeO}_{4}$ Nanoceramic Particles by Soft Chemical Routes, International Journal of Applied Science and Engginering, India : Karunya University

Wahyudi, I., 2008, Pengaruh Pemanasan Pada Sintesis Osida Mangan Melalui Proses Sol Gel, Skripsi, Padang : Universitas Andalas 